C. Zhang, T.J. Owens, and Y.H. Song, 2006, "On the performance of densified DVB-H single frequency networks", International Journal of Mobile Network Design and Innovation, Vol. 1, Issue 3/4, pp224-233

Publisher: Inderscience

Original published version at: http://dx.doi.org/10.1504/IJMNDI.2006.012092

\title{
On the performance of densified single frequency networks for DVB-H
}

Zhang, C., Owens, T.J., and Song Y-H

\begin{abstract}
The broadcasting of TV programs to the mobile phone can be enabled by the newly developed technology called DVB-H (Digital Video Broadcasting for Handheld). Because of the scarcity and cost of frequency resources, frequency reuse needs to be considered when rolling out DVB-H networks. By simulcasting the same content from several transmitters, a single frequency network (SFN) can provide a good coverage and good frequency efficiency. In this paper, the performance of densified SFN networks is analysed in terms of the coverage probability under different coverage requirements with and without frequency reuse. A dichotomy searching approach is used to determine the optimal cell radius for a cell in densified SFNs for a given network topology. Based on the optimal cell radius map and SFN gain map generated from the simulation results, guidelines on how to avoid the potential pitfalls in configuring the parameters of a densified SFN network and the optimisation of these parameters in terms of minimising the cost of the network are proposed for a range of predefined network parameters.
\end{abstract}

\section{INTRODUCTION}

The DVB-H standard [1] has been developed specifically for broadcasting to handheld terminals. The DVB-H 4K FFT mode provides enhanced performance in mobile reception compared to the $8 \mathrm{~K}$ mode in DVB-T [1]. In particular, it exploits time slicing to reduce the power required to receive a broadcast service on a handheld terminal. Low power DVB-H transmitters are being developed in the INSTINCT project [2] that will allow localized broadcasting and the co-siting of DVB-H and cellular telecommunications transmitters reducing the cost of DVB-H network rollout. This introduces the possibility of cellular DVB-H broadcasting that means the distance between the transmitters is much less than that of conventional national broadcasting transmitters. One model for deployment of an open platform for convergence services is the deployment of densified DVB-H broadcasting networks alongside GPRS/UMTS telecommunications networks. 
A single frequency network (SFN) is composed of several transmitters sending the same program using one frequency block. The signals will arrive at the receiver with different delay and amplitude. Based on the OFDM modulation scheme in DVB-H, a guard interval is inserted prior to symbols to combat the inter-symbol interference (ISI) caused by the multi-path effect. A signal with delay less than the guard interval will contribute to the useful signal power but a signal with delay greater than the guard interval will cause Inter-Symbol Interference (ISI) and produce self-interference in the network. When frequency reuse is applied to other local SFNs, the network will also experience external interference coming from other SFNs using the same frequency block. How to configuring the network parameters to minimise the external and internal interference is a main problem addressed in this paper.

This paper is organised as follows: Section II specifies the network parameters defined and used in the simulation study; section III explains the system model used in this paper; section IV describes a coverage planning process to compute the coverage probability for a small area in a densified single frequency DVB-H network; section V proposes a dichotomy searching approach to finding the optimal cell radius for a predefined network for cell dimensioning in SFN. Section VI shows the numerical results for densified SFNs with and without frequency reuse. Based on the constructed optimal cell radius map and SFN gain map, the performance of the densified network in terms of SFN gain with and without frequency reuse is analysed. In section VI, network design rules are formulated from the simulation results as the conclusions to the work.

\section{NETWORK PARAMETERS DEFINITION}

The network parameters play an important part in DVB-H network planning. This section defines the network parameter values and their ranges used in this paper.

The objective of network planning in DVB-H is to evaluate the coverage area in the studied area under predefined network parameters. In this paper, the area covered is defined in terms of the following:

Coverage degree definition: Three levels of coverage are defined in [6].

Level 1: Receiving location

The smallest unit is the receiving location. A transmitter covers a location if the strength of the wanted signal at the location is high enough to overcome the noise and interference present for a given percentage of time.

Level 2: Small area coverage (pixel)

A pixel can be taken to be $100 \mathrm{~m}$ by $100 \mathrm{~m}$ or $200 \mathrm{~m}$ by $200 \mathrm{~m}$ of the studied area depending the type of area studied. The studied area is decomposed into such pixels, a pixel is defined as "good" if $95 \%$ of the area of the pixel is covered and "acceptable" if $70 \%$ of the area of the pixel is covered [6].

Three pixel coverage degrees are defined in terms of the different coverage scenario requirements in this paper: 
Pixel Coverage Grade I (PCGI): If 95\% of a pixel area is covered by the signal, then the pixel is a covered pixel with PCGI.

Pixel Coverage Grade II (PCGII): If 90\% of a pixel's area is covered by the signal then the pixel is a covered pixel with PCGII.

Pixel Coverage Grade III (PCGIII): If 70\% of a pixel's area is covered by the signal, then the pixel is a covered pixel with PCGIII.

\section{Level 3: Coverage area}

The coverage area of a transmitter or a group of transmitters is made-up of the sum of the small areas (pixels) in which a given percentage (70\% or $90 \%)$ coverage is achieved.

Three whole area coverage degrees also are defined in this paper to express the coverage of the whole of the studied area:

Area Coverage Grade I (ACGI): $95 \%$ of the pixels in the studied area are covered in terms of one of the predefined pixel coverage grades. This is suitable for densely populated areas like busy urban areas; shopping malls, airports etc.

Area Coverage Grade II ( ACGII): $90 \%$ of the pixels in the studied area are covered in terms of one of the predefined pixel coverage grades. This is for urban area planning.

Area Coverage Grade III ( ACGIII): $70 \%$ of the pixels in the studied area are covered in terms of one of the predefined pixel coverage grades. This grade can be suitable in rural area planning.

It should be noted that the area coverage grade must be used with the pixel coverage grade. In this document, ACGI is used with PCGI, ACGII with PCGII, and ACGIII with PCGIII in the default setting.

The other parameters are listed in Table 1.

Table 1: The parameters used in the simulations

\begin{tabular}{|l|l|}
\hline Parameters & Value \\
\hline Transmitter frequency $(\mathrm{Mhz})$ & 600 \\
\hline Transmitter power $(\mathrm{dB})$ & $10 \sim 45$ \\
\hline $\begin{array}{l}\text { Transmitter antenna height } \\
(\mathrm{m})\end{array}$ & $20 \sim 300$ \\
\hline Receiver height $(\mathrm{m})$ & 1.5 \\
\hline Transmitter antenna pattern & Omni \\
\hline Symbol time $(\mu \mathrm{s})$ & 448 \\
\hline Guard interval time $(\mu \mathrm{s})$ & $14(1 / 32$ of symbol time); $112(1 / 4$ of symbol \\
time $)$
\end{tabular}




\begin{tabular}{|l|l|}
\hline Shadowing deviation $(\mathrm{dB})$ & 8 \\
\hline C/I threshold $(\mathrm{dB})^{*}$ & $5 \sim 30$ \\
\hline $\begin{array}{l}\text { Burst on-time duration in a } \\
\text { burst cycle }\end{array}$ & 0.5 \\
\hline
\end{tabular}

*The $\mathrm{C} / \mathrm{I}$ threshold is set according to Table 6.1 of [1]. In [1], the minimum $\mathrm{C} / \mathrm{N}$ is $5.4 \mathrm{~dB}$, and the maximum is $27 \mathrm{~dB}$, in the simulations the $\mathrm{C} / \mathrm{I}$ threshold value is rounded to the nearest integer value over the whole range of $5 \sim 30 \mathrm{~dB}$.

Several parameters listed in Table 1 need to be explained:

Burst on-time duration in a burst cycle: Although the transmitter in a DVB-H network transmits all the service bursts in the cycle time, the DVB-H receiver only receives the burst it is interested in and ignores the others in one cycle time. Because of this, the burst on-time duration in a burst cycle for one service will effect the performance of the planned network.

Shadowing deviation: In a terrestrial broadcasting system, the link quality is effected by the slow variation of the mean signal due to the shadowing from buildings and trees. The communication system performance will depend only on shadowing if the radio receiver is able to average out multi-path fading. Based on empirical measurements, this shadowing effect can be modeled by a lognormal distribution for outdoor and indoor environments. The typical standard deviation for this lognormal shadowing is $6 \mathrm{~dB}-12 \mathrm{~dB}$.

C/I threshold: In evaluating the performance of the SFN, the C/I threshold at which the receiver can receive a predefined quality of service $(\mathrm{QoS})$ is a key parameter effecting the coverage of the network. This threshold characterises the ability of the receiver to demodulate the signal under different channel profiles and this ability mainly depends on the receiver design. In [5], the imperfect symbol synchronization, frequency synchronization, fading and phase noise, can act as noise and increase the C/I threshold required for a predefined QoS. With a different algorithm (Synchronization, channel estimation etc.) in the receiver, a different $\mathrm{C} / \mathrm{I}$ requirement will apply for the same channel profile. In this paper, a range of $\mathrm{C} / \mathrm{I}$ thresholds is applied to the simulation based on the simulation results in the DVB-H standard [1] rather than computing the network performance based on one receiver design. The basic assumption made in this paper is that the threshold for receiving a predefined QoS is unchanged for the whole studied area.

\section{SYSTEM MODEL}

In a terrestrial broadcasting system, the link quality is effected by the slow variation of the mean signal due to the shadowing from buildings and trees and is also effected by the multi-path signals coming with different delays and amplitudes. In this paper, it is assumed that the radio receiver is able to average out multi-path fading and then the communication system performance will depend only on the shadowing effect. Based on empirical measurements, this shadowing effect can be modeled by a lognormal 
distribution for outdoor and indoor environments.

\section{C/I RATIO AND OUTAGE PROBABILITY}

In a SFN, the receiver combines the different signal components coming from the different transmitters in the SFN network. For the ith signal component the received signal power $P_{i}$, may contribute to the useful part of the combined signal or the interfering part or to both parts depending on the relative delay. The ratio between the useful contribution, $U_{i}$ and the interfering contribution, $I_{i}$, of the $i$ th signal component is modeled by the weighting function $w\left(\tau_{i}-\tau_{0}\right)$ where $\tau_{i}$ represents the signal delay relative to starting point of the receiver detection window $\tau_{0} \quad$ [3] [4].

$$
\begin{aligned}
& U_{i}=w\left(\tau_{i}-\tau_{0}\right) \cdot P_{i} \\
& I_{i}=\left(1-w\left(\tau_{i}-\tau_{0}\right)\right) \cdot P_{i}
\end{aligned}
$$

For the weighting function $w(\Delta \tau)$, the following quadratic form has been suggested in [7]:

$$
w(\Delta \tau)=\left\{\begin{array}{cc}
0 & \text { if } \Delta \tau \leq 0 \\
1 & 0<\Delta \tau \leq T_{g} \\
\left(\frac{T_{u}-\Delta t+T_{g}}{T_{u}}\right)^{2} & \text { if } T_{g}<\Delta \tau<T_{F} \\
0 & \text { if } \Delta \tau \geq T_{F}
\end{array}\right.
$$

Where $T_{u}$ and $T_{g}$ denote the time duration of the useful signal and the guard interval time. $T_{F}$ is the inverse of the pass-band in $\mathrm{Hz}$ of the frequency domain interpolation filter which the constellation equalization and coherent detection is based on in the channel estimation process. This value cannot exceed $T_{u} / 3$ [7]. In [7], it is assumed that $T_{F}=\frac{T_{u}}{3}$.

If the index set of the transmitters of the studied SFN is represented by $\Omega=\{1, \ldots, N\}$ and the transmitters of other SFNs operating at the same frequency are denoted by $\Psi=\{1, \ldots, \mathrm{M}\}, P_{i}$ is the received signal power coming from $i$ th transmitter and usually $P_{i}(\mathrm{~dB})$ can be represented by a lognormal distribution variable with a mean value of $m_{p}$ and a standard deviation of $\sigma_{p}$, the mean of $w \cdot P_{i}$ is $m_{P}+10 \cdot \log (w)$ and the standard deviation is $\sigma_{p}$. If the background noise power is $N_{0}$, the $\mathrm{C} / \mathrm{I}$ ratio can be written as [4]: 


$$
\begin{aligned}
& \Gamma=\frac{U}{I}=\frac{\sum U_{i}}{\sum I_{i}} \\
& =\frac{\sum_{i \in \Omega} P_{i} \cdot w\left(\tau_{i}-\tau_{0}\right)}{\sum_{i \in \Omega} P_{i} \cdot\left(1-w\left(\tau_{i}-\tau_{0}\right)\right)+\sum_{i \in \Psi} P_{i}+N_{0}}
\end{aligned}
$$

The total useful signal $U$ and the interference signal $I$, ignoring $N_{0}$ in the presence of inner interference and outer interference, can be represented by lognormal distribution variables with parameters, $m_{u}$ and $\sigma_{u}, m_{I}$ and $\sigma_{I}$, respectively. In this case, the $\mathrm{C} / \mathrm{N}$ ratio in $\mathrm{dB}$ has a normal distribution with mean $m_{\Gamma}=m_{u}-m_{I}$ and standard deviation $\sigma_{\Gamma}^{2}=\sigma_{u}^{2}+\sigma_{I}^{2}$, assuming $U$ and $I$ are uncorrelated. The performance of a DVB-T network is usually measured by the coverage probability, $P_{c T}$, which is defined as the probability that the $\mathrm{C} / \mathrm{I}$ ratio exceeds a system specific protection ratio $\gamma_{0}$ :

$$
P_{C T}=\operatorname{Pr}\left\{\left(\Gamma>\gamma_{0}\right\}=1-P_{o T}\right.
$$

Compared to the DVB-T receiver that receives the video stream all the time, the DVB-H receiver only receives the stream for the specified time slice and the burst duration has a maximum value in one time period that is set in the encapsulator. If in a DVB-T receiver the outage probability for one location is $P_{o T}$, the ratio of the burst duration to one reception period in the DVB-H receiver is $\beta$, the outage probability for DVB-H receiver $P_{o H}$ will be

$$
P_{o H}=\beta \cdot P_{o T}
$$

Then the coverage probability $P_{c H}$ in the DVB-H network

$$
P_{C H}=\operatorname{Pr}\left\{\Gamma>\gamma_{0}\right\}=1-P_{O H}=1-\beta \cdot P_{O T}
$$

and the $P_{\text {oT }}$ for which the $\mathrm{C} / \mathrm{I}$ ratio is less than the threshold is

$$
P_{O T}=\operatorname{Pr}\left\{\Gamma<\gamma_{0}\right\}=1-\int_{\gamma_{0}}^{\infty} \frac{1}{\sqrt{2 \pi} \sigma_{\Gamma}} \cdot \exp \left(\frac{-\left(\Gamma-m_{\Gamma}\right)^{2}}{2 \sigma_{\Gamma}^{2}}\right) d \Gamma
$$

\section{STATISTICAL COMBINATION MODEL FOR LOGNORMAL VARIABLES}

The sum of the interference signal power $I_{i}$ and the contributed signal $U_{i}$ is required to compute the C/I ratio in equation (3). As $I_{i}$ and $U_{i}$ can be represented by lognormal distribution variables, the Monte-Carlo method is the most accurate way to compute the distribution of the sum of several lognormal variables. However, this method is 
time consuming and usually an approximation method is used for simulation purposes. Although there is no exact mathematical expression to describe the distribution function of the sum of lognormal variables there are several approximation methods based on the assumption that the sum of lognormal variables is a lognormal variable, i.e., the Fenton-Wilkinson, Schwarts-Yeh [8], Farley [10], t-LNM [7] and CH method [9]. The approximation accuracy usually depends on the number of interference sources and their deviation, etc [6].

Schwarts andYeh [8] show that the Monte Carlo simulation agrees quite closely with the assumed Gaussian cumulative distribution function (cdf) in the range of 0.1 to 99 percent. In this paper, a simplified Schwarts-Yeh method [11] is used to compute the sum of the lognormal distribution variables. From simulation experience, this method has a relative error below 10\% compared with the Monte Carlo simulation result if the deviation of all lognormal components is $8 \mathrm{~dB}$ and the number of the sum of the components does not exceed 120 .

\section{COVERAGE PLANNING PROCEDURE FOR ONE PIXEL AREA}

In the coverage planning procedure presented below only one signal coming from one transmitter is assumed and if no terrain data is available, this signal can be taken as line of sight (LOS). The following procedure (Figure 2) illustrates how the outage probability for one pixel area is obtained.

1. Set the parameters to be used in the simulation.

2. If terrain data is not used then go to step 4 without terrain data, otherwise, continue to the next step.

3. Load the terrain model.

4. Use ITU P1546 to compute the path loss.

5. Compute the signal delay time with respect to the first arrived signal from the all the transmitters to the pixel selected.

6. Set the start time of the FFT window to be aligned with the position of the start of the first arrived signal and set the first step size $\tau_{0}=0$.

7. If the maximum delay is less than the guard interval time, then set the loop limit $=1$, otherwise set the loop time limit $=2 \mathrm{~N}-1$ where $\mathrm{N}$ is the number of the transmitters from the same SFN.

8. Move the start time of the FFT window to the position obtained by adding the step size to the last position of the FFT window.

9. Compute the weight coefficient of the signal component.

10. Use the simplified SY method to compute the mean and the deviation of the C/I value.

11. Set the next step size $=\tau_{i}, i=1 \ldots 2 \mathrm{~N}-1$.

12. If the loop time is less than the loop limit then go to 6 , otherwise go to the next step.

13. Find the maximum mean $\mathrm{C} / \mathrm{I}$ computed in the loop and calculate the outage probability as the pixel outage probability. 
14. If not all the pixels in the studied area are computed, go to 5; otherwise go to next step.

15. Graphically display the result.

Because the receiver has different design characteristics for different manufacturers, a general receiver model is difficult to obtain. In this paper, the $\mathrm{C} / \mathrm{I}$ ratio is computed based on the maximum $\mathrm{C} / \mathrm{I}$ the receiver can get in the presence of the contributed and interference signals. Because it is assumed in this paper that all the transmitters have the same transmitting power and all the antennas have the same height and are omni direction, the first arrived signal at one receiving location is also the strongest one without a terrain model. So in this case, the maximum C/I ratio can be obtained when the start time of FFT window is aligned with the first received signal. And in this case, in step $7, \mathrm{~N}=1$ is set.

If the transmitter powers are different from the transmitters in the network or the antenna configuration (i.e. the height or antenna pattern) is not same, the signal power received at one location will not only depend on the distance of the transmitter, but also the power of the transmitter and the antenna height and direction etc. In such a case, the start of the FFT window at the start of first arrived signal cannot give the maximum C/I ratio and a search for a better start time for the FFT window should be made.

Raland and David [12] have pointed out that the modeling of the receiver behavior in network coverage simulations has to be in line with the synchronization strategies and the treatment of inter-symbol interference in the receivers. In [12], several receiver synchronization strategies have been compared and discussed. Among these strategies, the "maximum C/I" is an idealized optimal strategy that will take much time to be computed. A simple but time-consuming approach would be to scan the time period of interest within an appropriate step size, calculate the $\mathrm{C} / \mathrm{I}$ ratio for each sampling point and use the time position with the maximum $\mathrm{C} / \mathrm{I}$ ratio as the reference. But setting the step size based on a trade-off between accuracy and computational effort is not easy. Raland and David [12] also proposed another strategy to find the maximum C/I ratio position based on the observation that the maximum $\mathrm{C} / \mathrm{I}$ ratio is always found at a position where the FFT window is aligned with the start, or the end of one of the incoming signals for the symbol under consideration. Checking of all these possible positions, which amounts to $2 \mathrm{~N}$ evaluations of $\mathrm{C} / \mathrm{I}$ ratios for $\mathrm{N}$ signals, can give the maximum $\mathrm{C} / \mathrm{I}$ ratio position.

The FFT window position-searching algorithm in this paper uses the maximum C/I ration position searching method of [12]. If the transmitter power or the antenna diagram (height and direction) is not the same for all transmitters, then this algorithm is used to calculate the maximum mean $\mathrm{C} / \mathrm{I}$ ratio the receiver can receive using the sum of the log-normal distribution variable method. The step size is set as $\tau_{i}, i=0,1 \ldots 2 \mathrm{~N}-1$. Figure 1 gives an example of the 3 echoes coming from 3 transmitters with different 
delay. $\tau_{0}$ is zero as FFT window aligned with the first arrived signal. $\tau_{i}, i=1 \ldots 4$, is set according to the start or the end of each signal.

Figure 2 gives the flow chart for a one pixel outage probability computation only. For the other pixels in the studied area, the computation process is the same. 


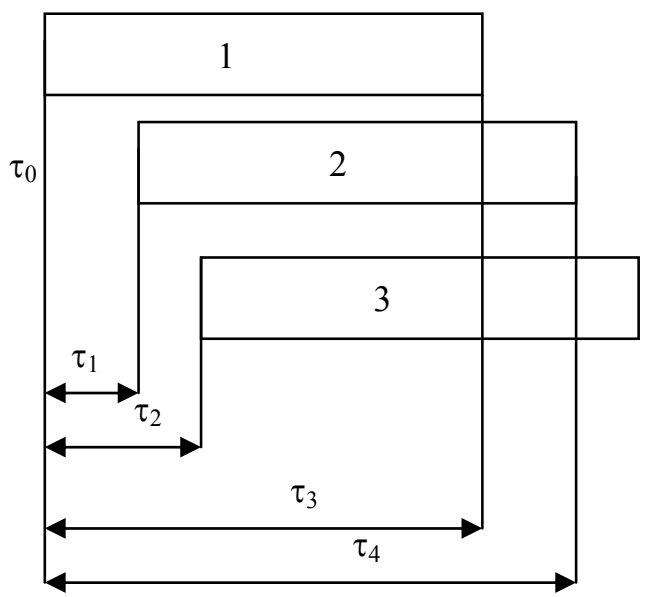

Figure 1: The step size $\tau_{i}, i=0,1 \ldots 4$, for the FFT window start position in searching algorithm for the maximum $\mathrm{C} / \mathrm{I}$ ratio (3 echoes from 3 transmitters) 


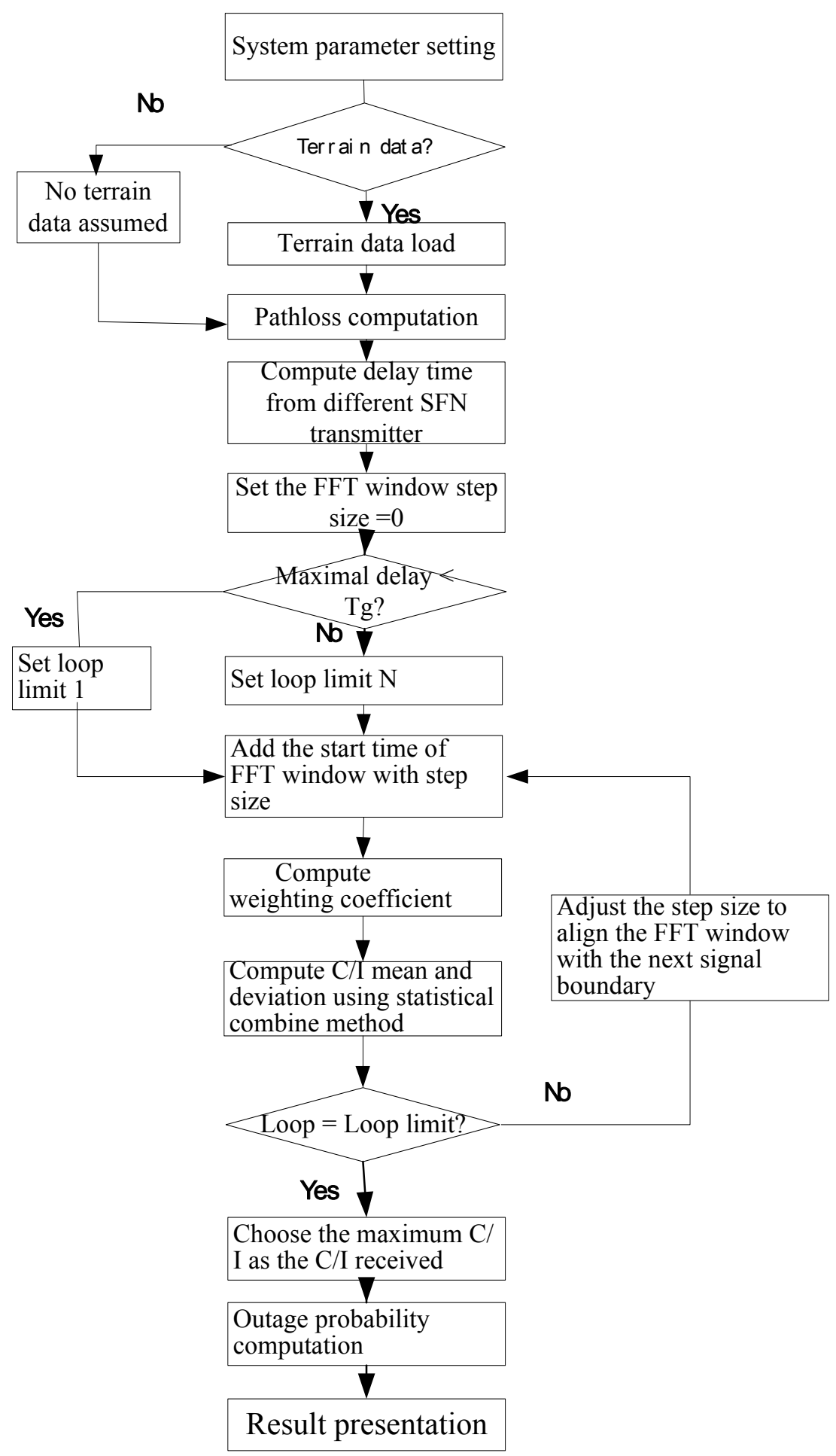

Figure 2: Flow chart of the coverage simulation for one pixel area

\section{CELL DIMENSIONING AND SFN GAIN}

In the wide area SFN network, after all the network parameters have been specified, the optimal cell radius for one hexagonal cell can be identified. The optimization criterion for cell radius is that the ratio of the area composed of the locations within the cell which can receive the minimum $\mathrm{C} / \mathrm{I}$ ratio required by the receiver to achieve a 
predefined QoS to the total studied area of the hexagonal cell is the ratio predefined for covering the studied area and the cell radius is the largest one that gives this defined ratio.

The method used to calculate the optimal cell radius is the dichotomy searching method. A crucial assumption of this method is that the pixel ratio satisfying the predefined ratio threshold is unimodal in case of frequency reuse and monotonically decreasing in case of no frequency reuse. This assumption is based on the observation of the simulation results of antenna height in the range of $20 \mathrm{~m}$ to $300 \mathrm{~m}$ and the transmitter power in the range of $10 \mathrm{~dB}$ to $45 \mathrm{~dB}$. For illustration purposes, Figure 3 shows an example of the pixel coverage ratio for a SFN of size $=3$ with no frequency reuse and Figure 4 shows an example of the pixel coverage ratio for a SFN of size $=3$ and Reuse factor $=3$, in these two examples, it can be observed that the results fit the assumption very well.

Figure 3 shows the pixel coverage ratio monotonically decreasing as the radius increases, ACGI and ACGII have faster decreasing curves than ACG III, this is because for a higher pixel coverage ratio, the $\mathrm{C} / \mathrm{I}$ ratio is more sensitive to the interference and attenuation of the contributed signal. Figure 4 shows the pixel coverage ratio reaches a peak value as the cell radius increases. This is because in the situation where outer interference exists, the interference is quite strong compared to the contributed signal for a small cell radius, so the $\mathrm{C} / \mathrm{I}$ ratio in the studied area starts at small value for small radiuses but as the radius increases the interference attenuates more quickly than the contributed signal thanks to the number of transmitters in the SFN which leads to the C/I ratio in the studied area increasing. As the contributed signals also attenuate as the radius increases further, the $\mathrm{C} / \mathrm{I}$ ratio will eventually decrease and this leads to the $\mathrm{C} / \mathrm{I}$ ratio monotonically decreasing. 

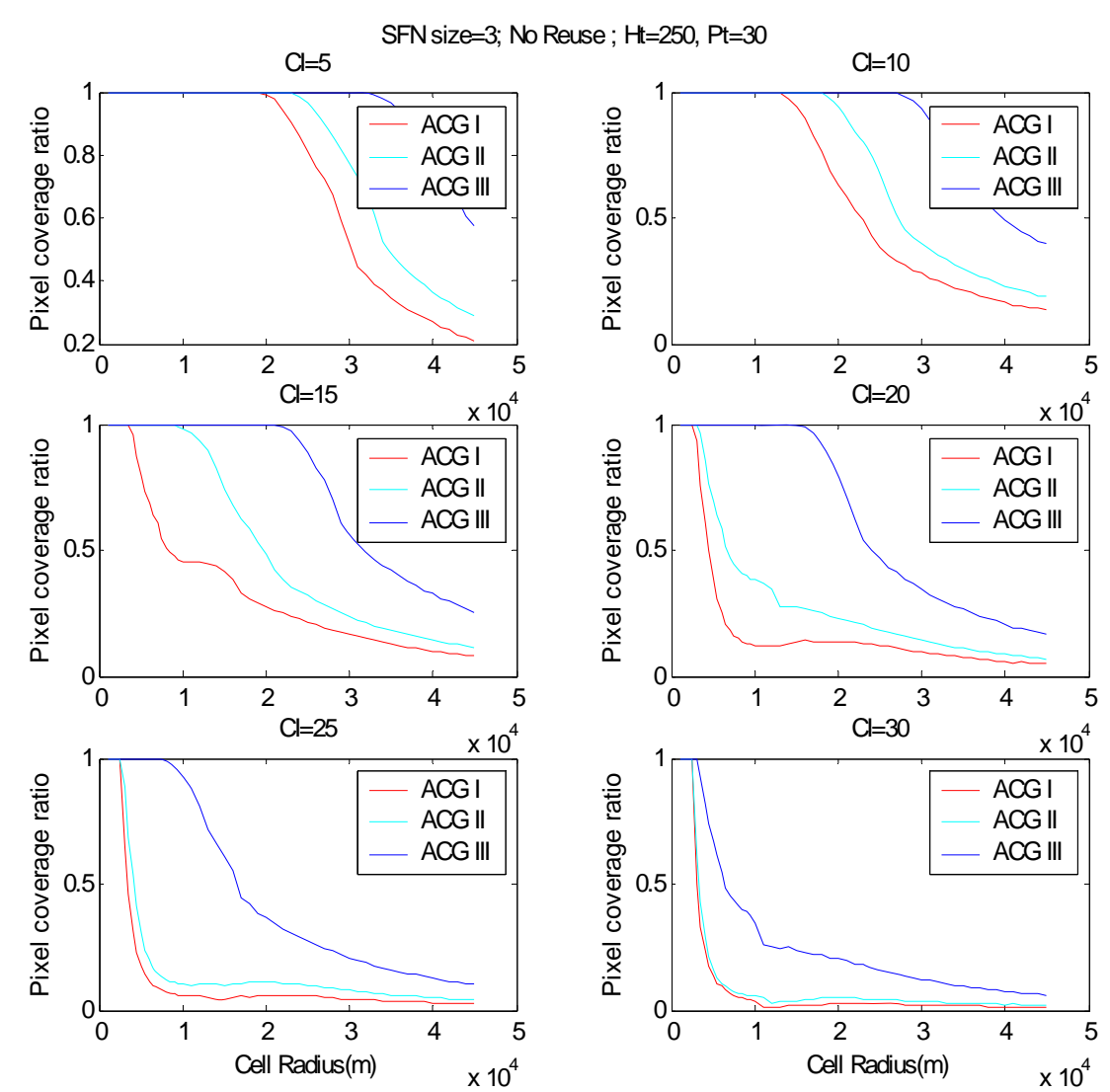

Figure 3: The pixel coverage ratio for SFN size $=3$ with no frequency reuse
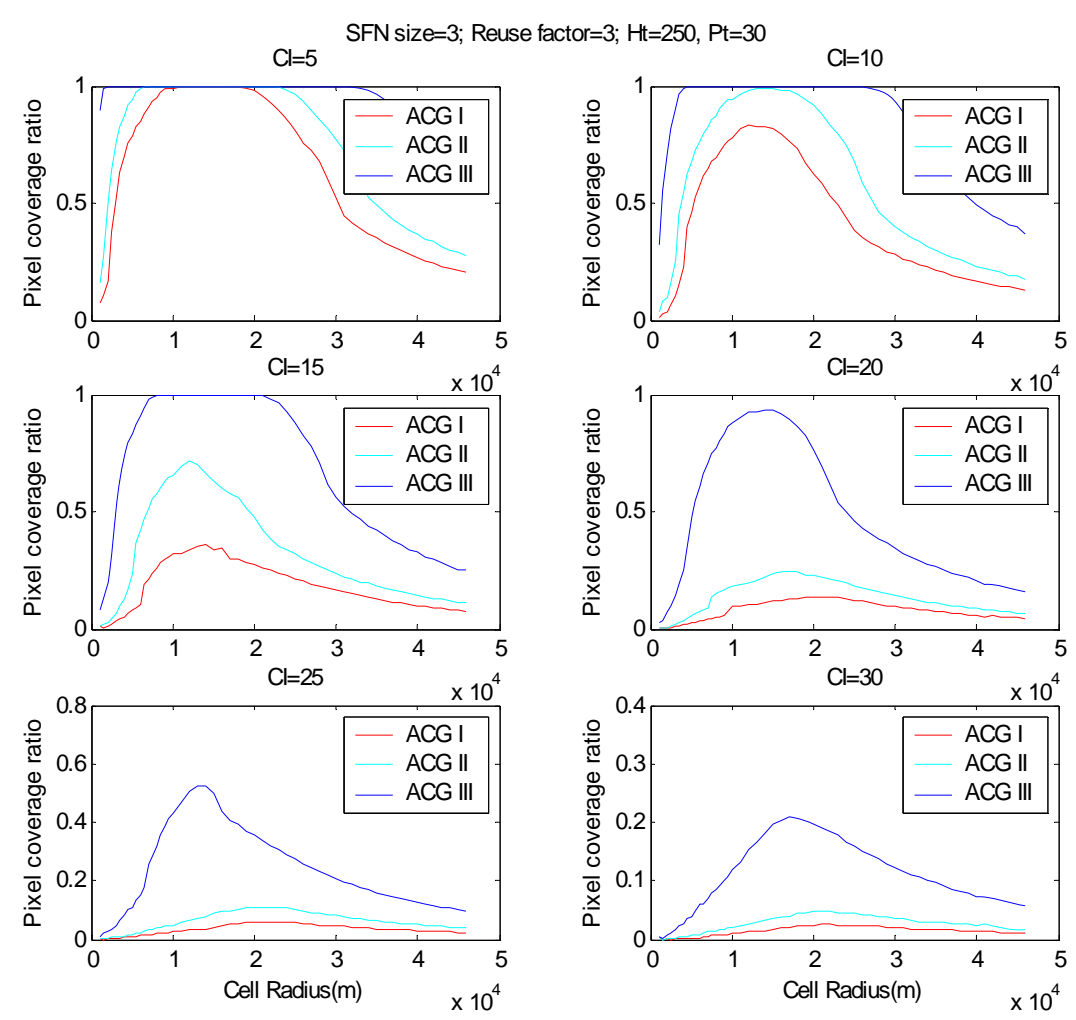

Figure 4: The pixel coverage ratio for $\mathrm{SFN}$ size $=3$ and Reuse factor $=3$ 


\section{Dichotomy searching method:}

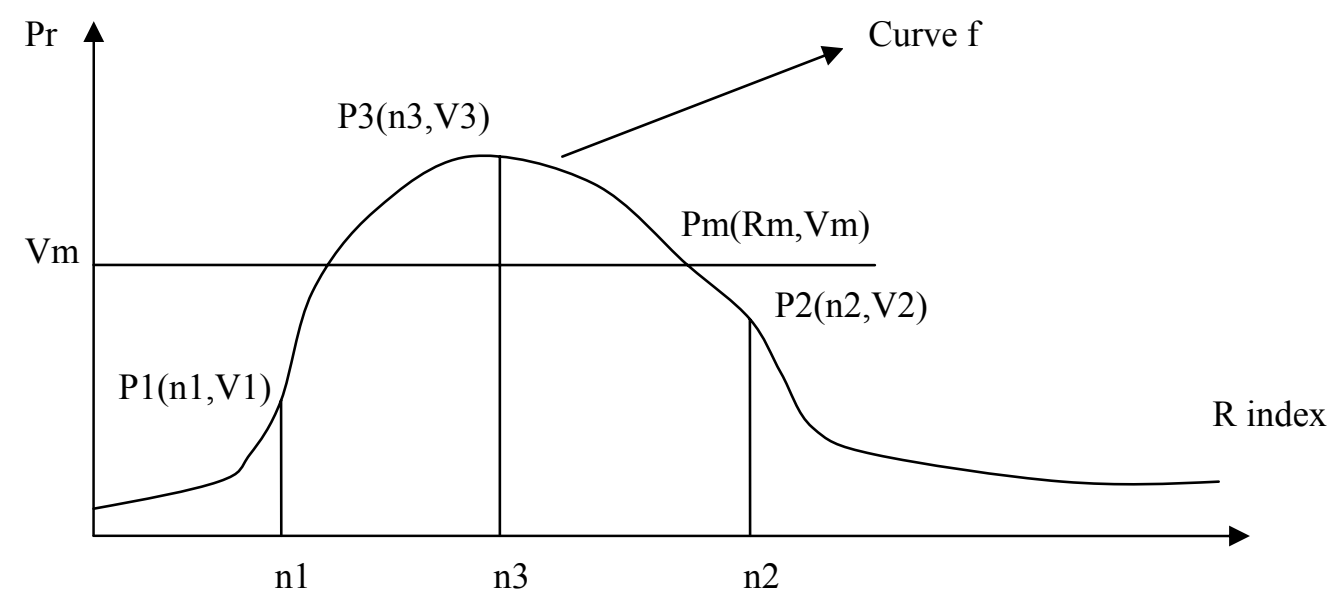

Figure 5: The unimodal shape of the specific pixel ratio curve $\mathrm{f}$ in terms of the cell radius $\mathrm{R}$ index

Figure 5 gives an example of a specific pixel ratio curve $\mathrm{f}$ in terms of the cell radius index. The vertical coordinate represents the specific pixel ratio in Figure 5; The specific pixel ratio means the pixel ratio of the number of covered pixels to the number of pixels in the coverage area studied. The horizontal coordinate represents the index of the searching radius vector that increases in value from $500 \mathrm{~m}$ to $80 \mathrm{~km}$ in steps of $1 \mathrm{~km}$. (In the case of the highest transmitter power and highest antenna height, used in this paper, the optimal radius will be less than $80 \mathrm{~km}$ in the testing scenarios). The dichotomy searching method is an iterative searching process that starts at the points $\mathrm{P} 1(\mathrm{n} 1, \mathrm{~V} 1)$ and $\mathrm{P} 2(\mathrm{n} 2, \mathrm{~V} 2)$ where $\mathrm{P} 1$ and $\mathrm{P} 2$ shown in Figure 5 are two arbitrary points but $\mathrm{P} 1$ is to the left of $\mathrm{P} 2$. After each iteration, a next radius index variable named index_R is set to find a new point P3(n3,V3) in the next step. Then according to the relative position of the points $\mathrm{P} 1, \mathrm{P} 2$ and $\mathrm{P} 3$ in the curve $\mathrm{f}$, the old value of $\mathrm{P} 1$ or $\mathrm{P} 2$ will be replaced by $\mathrm{P} 3$ and the searching range reduced. Here $\mathrm{n} 1, \mathrm{n} 2$ and $\mathrm{n} 3$ are radius indices and $\mathrm{V} 1, \mathrm{~V} 2$ and $\mathrm{V} 3$ are the specific pixel ratios for points $\mathrm{P} 1, \mathrm{P} 2$ and $\mathrm{P} 3$ respectively.

Dichotomy searching means that when searching between points $\mathrm{P} 1$ and $\mathrm{P} 2$, the next radius index will be set to be in the middle of these two points. The method is to find the point $\mathrm{Pm}(\mathrm{Rm}, \mathrm{Vm})$ in the deceasing part of the curve $f$, where $\mathrm{Rm}$ is the corresponding radius and $\mathrm{Vm}$ is defined as the pixel ratio threshold of the studied area "covered" in the sense ACG I, II or III. In the dichotomy searching method, the range of the search can be reduced in two adjacent cell radius indices of the searching radius vector because of the radius step of $1 \mathrm{~km}$ and the fact that the searching is based on the radius index. To find the exact value of the optimal radius, if this radius exists, cubic splines interpolation based on this reduced range of search needs to be carried out.

Figure 7 gives the process for calculating the optimal cell radius that comprises the 
following steps:

1. Generate the network topology based on the parameters set.

2. Generate the path loss based on the parameters input.

3. Set $\mathrm{n} 1=2, \mathrm{n} 2=4$ and $\mathrm{n} 3=5$ of the points $\mathrm{P} 1(\mathrm{n} 1, \mathrm{~V} 1)$, $P 2(n 2, V 2)$ and $P 3(n 3, V 3)$ that are at the start of the curve f; Set $R_{-}$index $=[n 1 n 2 n 3]$ that indicates that the radius indices $\mathrm{n} 1, \mathrm{n} 2$ and $\mathrm{n} 3$ of points $\mathrm{P} 1, \mathrm{P} 2$ and P3 need to be computed for the values of $\mathrm{V} 1, \mathrm{~V} 2$ and $\mathrm{V} 3$.

4. Compute the specific pixel ratio for the radius index in the vector R_index.

5. Use the dichotomy searching method to find out the next index variable index $\mathrm{R}$ to be computed, and reset $\mathrm{R}$ _index to indexR.

6. If indexR $=-1$, then the searching range has reached its minimum possible value with two adjacent cell radius indices, in this case go to next step, otherwise, go to step 5 to compute the specific pixel ratio of radius index in vector $\mathrm{R}$ _index.

7. If the maximum difference between $\mathrm{V} 1$ and $\mathrm{V} 2$ of points $\mathrm{P} 1$ and $\mathrm{P} 2$ is greater or equal to the $\mathrm{Vm}$ set by user, then interpolation will be carried out to get the optimal cell radius of $\mathrm{Pm}(\mathrm{Rm}, \mathrm{Vm})$; otherwise set the radius $=-1$ to indicate that no cell radius was found.

8. End

Figure 8 shows a detailed flow chart of the dichotomy searching method used in step 6 of the optimal cell radius calculation.

In the iterative process of the dichotomy searching method, the outcome of each step is the radius index to be computed for the next step, this including the radius index of test point $\mathrm{P} 3$. In some cases, from the previous step computation, even after the value of $\mathrm{V} 3$ of point $\mathrm{P} 3$ is known, because of the unimodal characteristic of the curve $\mathrm{f}$, the position of the point P3 cannot be decided yet. Taking case 2 of Figure 6 for example, the point $\mathrm{P} 3$ can be located at the both increasing and decreasing side of the curve $\mathrm{f}$. In such a case, further computation of the specific ratio of the point right before the point P3 is needed. So the searching process has two parts, with and without testing the point location. More detail of the searching process is explained in the following. The symbol "A->B" means set the value of the variable $B$ to the value of the variable A.

In following text, the variables $\mathrm{V}_{\text {old }}$ and $\mathrm{n}_{\text {old }}$ are the variables to store as the specific ratio and radius index in the last step. According to the location of the next searching point, two different searching scenario need to be carried out. One is the scenario that the next searching point location can be identified with the computed cell radius index; the other is that the further information need to be obtained to check the test point 
before the computed cell radius index.

\section{In the case of not testing the location of the point:}

(1) $\mathrm{n} 3>\mathrm{n} 2$, this indicates that the next radius index is out of the interval $(\mathrm{n} 1, \mathrm{n} 2)$.

a) V3 $>=$ V2: V3->V2; n3->n2; indexR $=$ indexR $+\mathrm{R} \_$step.

According to the curve characteristic of Figure 5, this means that the point P3 maybe on the increasing part of the curve, and this means the searching point $\mathrm{Pm}$ will be on the right side of the curve and a bigger radius needs to be computed. So the new radius index is set to an additional $\mathrm{R}$ _step where $\mathrm{R}$ _step is the predefined step for searching the radius index in a forward direction.

b) V3<V2: V3<V2<Vm: V3->Vold; n3->nold; testpoint $=1$. indexR $=\mathrm{n} 2-1$.

In this case, the point $\mathrm{P} 2(\mathrm{n} 2, \mathrm{~V} 2)$ can be on either the increasing side or the decreasing side of the curve and a further test needs to be done to identify on which side P2 is located. Case 1 in Figure 6 gives an example of the possible location of the points $\mathrm{P} 2$ and $\mathrm{P} 2$ '.

(1)

$$
\begin{aligned}
& \mathrm{V} 3<\mathrm{Vm}<\mathrm{V} 2 \text { : V2->V1; n2->n1; V3->V2; n3->n2; } \\
& \quad \text { indexR = Nnew; Nnew }=\text { n1+floor }((\mathrm{n} 2-\mathrm{n} 1) / 2) .
\end{aligned}
$$

Here floor(A) means round $A$ to the nearest integer less than or equal to A. The point Pm will be in the interval of the points $\mathrm{P} 1$ and $\mathrm{P} 2$. A new radius index is set in the middle point of $n 1$ and $n 2$.

(2) V2 $>$ V3 $>$ Vm: V3->V2; n3->n2; indexR = indexR+R_step;

Although V3 is less than the V2, searching should continue outside of $(\mathrm{n} 1, \mathrm{n} 2)$ until the point $\mathrm{Pm}$ is included in the interval of $(\mathrm{n} 1, \mathrm{n} 2)$.

(2) $n 3<n 2$ : This indicates the next radius index will be in the interval $(n 1, n 2)$.

a) $\mathrm{Vm}>\mathrm{V} 3>\mathrm{V} 2$ : V3->Vold; $\mathrm{n} 3->$ nold; testpoint $=1$; indexR $=\mathrm{n} 3-1$;

In this situation, the new point $\mathrm{P} 3$ could be on either side of the curve and further testing is needed to identify the location of P3 on the increasing part of curve or on the decreasing part. Case 2 in Figure 6 gives an example of the possible location of points $\mathrm{P} 3$ and $\mathrm{P} 3$.

b) $\mathrm{V} 3<\mathrm{V} 2$ : V3->V1; n3->n1; index_R $=$ Nnew;

As long as $\mathrm{V} 3<\mathrm{V} 2$, the point Pm must be in the interval of the points $\mathrm{P} 3$ and $\mathrm{P} 2$. 
c) $\mathrm{V} 3>\mathrm{Vm}>\mathrm{V} 2$ : V3- $>\mathrm{V} 1 ; \mathrm{n} 3->\mathrm{n} 1$; indexR $=$ Nnew;

This case is the same as the above case.

\section{In the case of testing the location of the point P2 or P3 (testpoint = 1):}

In this case, the point $\mathrm{P} 3(\mathrm{n} 3, \mathrm{~V} 3)$ is the point right before the point $\mathrm{P}_{\text {old }}\left(\mathrm{n}_{\text {old }}, \mathrm{V}_{\text {old }}\right)$ in last step or the current point P2. Through the comparison of V3 and Vold or V2, the location of the point P3 in last step or the point P2 in current step on the unimodal curve can be identified.

(1) $\mathrm{n} 3<\mathrm{n} 2$ and $\mathrm{V} 3<$ Vold: Vold- $>$ V1; nold- $>$ n1; testpoint $=0$; indexR $=$ Nnew;

In the case of $n 3$ less than $n 2$, this must be the case of testing the location of the point $\mathrm{P} 3$ in the last step. If $\mathrm{V} 3$ is less than the Vold, then it means the point P3 of the last step is on the right side of the curve.

(2) $\mathrm{n} 3<\mathrm{n} 2$ and V3 $>$ Vold: Vold- $>$ V2; nold $->\mathrm{n} 2$; testpoint $=0$; indexR $=$ Nnew;

This must be the case of testing the location of the point $\mathrm{P} 3$ in the last step. If V3 is greater than the Vold, then it means the point $\mathrm{P} 3$ of the last step is on the left side of the curve.

(3) $\mathrm{n} 3>\mathrm{n} 2$ and V3 $<$ V2: V2->V1;n2->n1; Vold- $>\mathrm{V} 2$; nold- $>$ n2;testpoint $=0$;

indexR = Nnew; This is the case of testing the location of the point $\mathrm{P} 2$ in the last step. If $\mathrm{V} 3$ is less than the $\mathrm{V} 2$, then it means point $\mathrm{P} 2$ is on the left side of the curve.

(4) $n 3>n 2$ and V3 $>$ V2: testpoint $=0$; indexR $=$ Nnew;

This is the case of testing the location of the point P2 in the last step. If $\mathrm{V} 3$ is greater than the $\mathrm{V} 2$, then it means the point $\mathrm{P} 2$ is on the right side of the curve.

The above analysis is based on a SFN with frequency reuse, for a SFN without the frequency reuse the flow chart is also applicable.
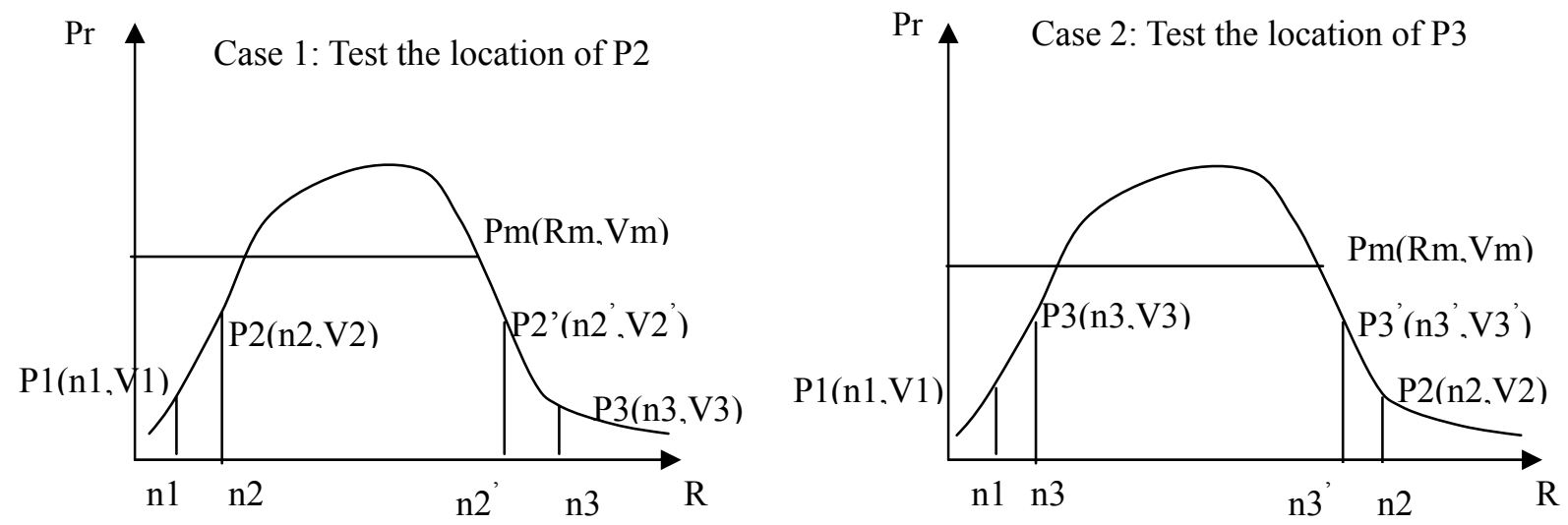
Figure 6: Two cases of the dichotomy search method that need to test the location of the point. ( the points $\mathrm{P} 3$ ' (n3',V3') and P2'(n2',V2') are the other possible locations of the points P2 and P3)

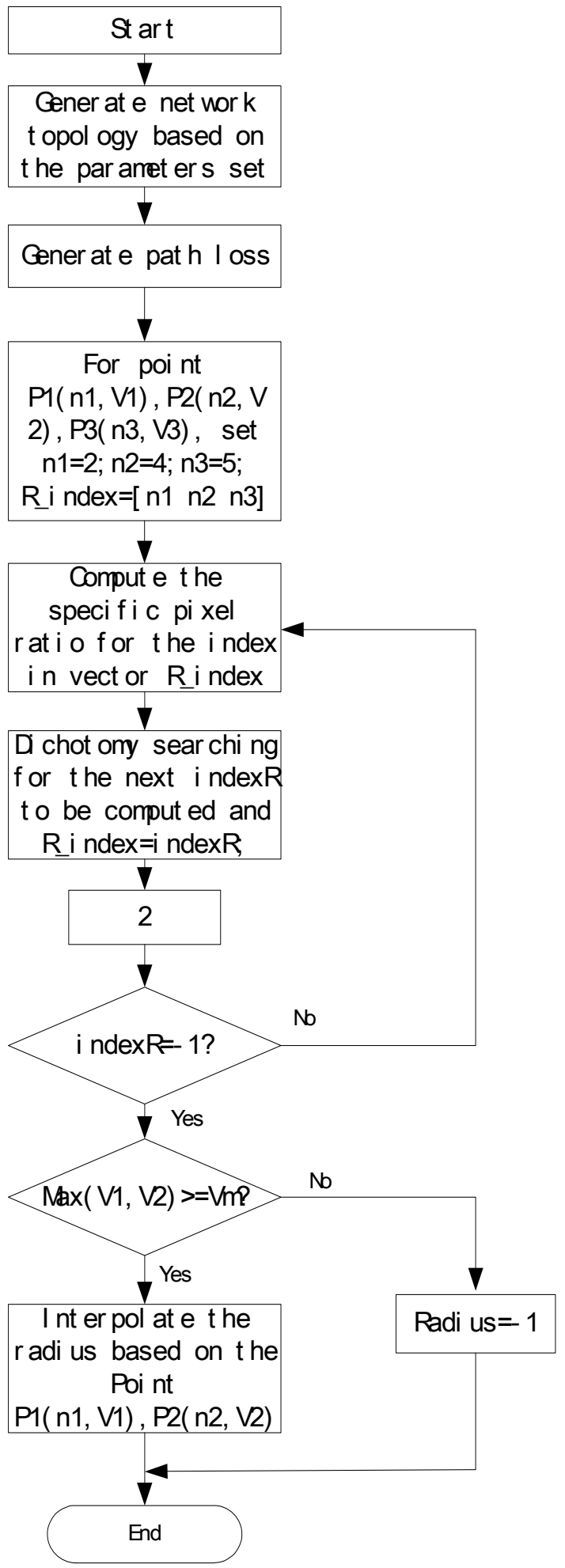

Figure 7: The flow chart for calculating the optimal cell radius 


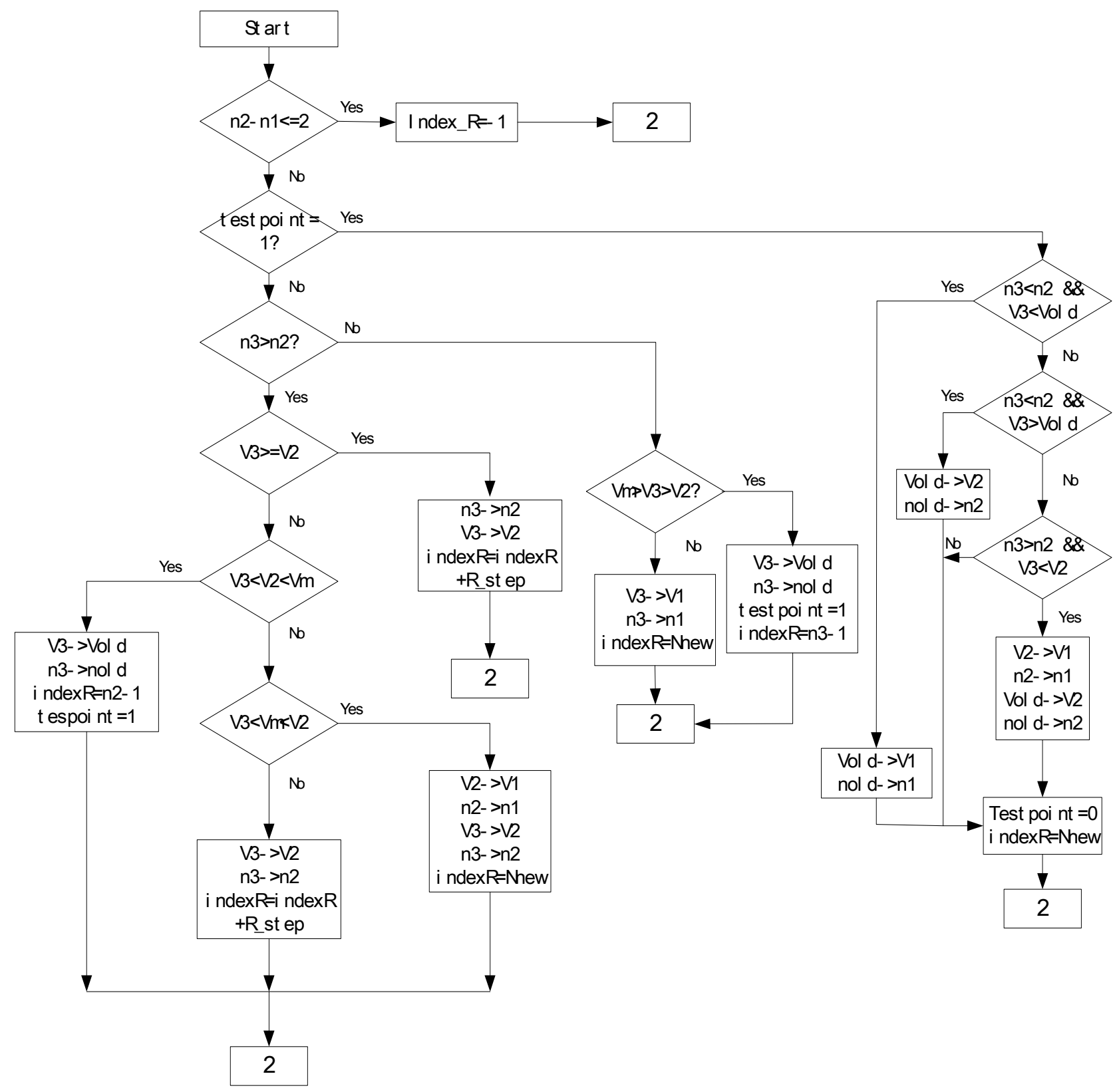

Figure 8: The dichotomy search flow chart for the next index of the new point P3

\section{SFN gain}

In the single frequency network, whether or not the signals coming from different transmitters can contribute to the useful signal in a C/I ratio computation depends on the signal delays with respect to the strongest signal. If a signal delay is less than the guard interval, this signal can give a positive contribution to the $\mathrm{C} / \mathrm{I}$ ratio at the receiver; otherwise it will act partly or fully like interference (Equation (3)). In an area where one transmitter signal is strongly attenuated, the contributed signals from 
other SFN transmitters could improve the received picture quality in this way. In the presence of inner interference or outer co-channel interference, such signals could contribute to the $\mathrm{C} / \mathrm{I}$ ratio, even when the interference is high. However, this contribution cannot give a $\mathrm{C} / \mathrm{I}$ ratio improvement as the useful contribution is suppressed by the interference.

SFN gain without frequency reuse

After the optimal cell radiuses for different network topologies and the different network parameter configurations have been obtained, a SFN gain comparison can be done based on the following SFN gain definition with different transmitters.

$$
\text { Gain }=\frac{\mathrm{R}_{\text {SFNn }}}{\mathrm{R}_{\text {Single }}}-1
$$

$\mathrm{R}_{\mathrm{SFNn}}$ means the optimal cell radius of one cell in a SFN with $\mathrm{n}$ transmitters; $\mathrm{R}_{\text {Single }}$ means a single transmitter optimal cell radius with the same network parameters.

SFN gain with a frequency reuse

In the presence of co-channel interference, the equation for SFN gain is:

$$
\text { Gain }=\frac{\mathrm{R}_{\text {SFNn }}}{\mathrm{R}_{\text {MFN }}}-1
$$

$\mathrm{R}_{\mathrm{SFNn}}$ is the optimal cell radius of one cell in a SFN size of $n$ with reuse factor $m$. $\mathrm{R}_{\mathrm{MFN}}$ is the optimal cell radius of a MFN with the same reuse factor $\mathrm{m}$ and the same network parameters.

\section{NUMERICAL RESULTS}

The two tiers SFN network layout (Figure 9) was used to evaluate the performance of the different sizes of SFN with different frequency reuse factors. The shapes of the SFNs of different sizes are showed in Figure 10. No terrain data was used in the simulations. The signal frequency was taken to be $600 \mathrm{Mhz}$ which is typical in UHF band. The transmitters power and antenna height are in the ranges listed in Table 1. The transmitter antenna pattern is omni-direction and the antenna height is same for all the transmitters in a network topology. 


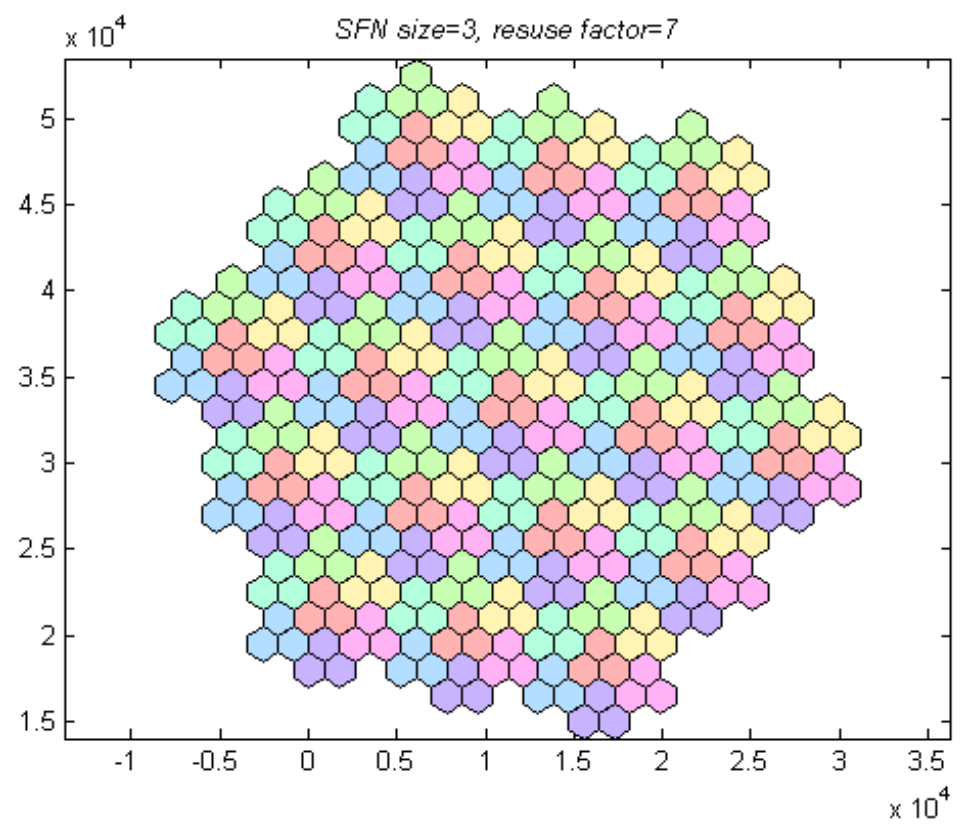

Figure 9: Two tiers SFN networks SFN size $=3$ and Reuse factor $=7$ (different colours represent different frequencies)
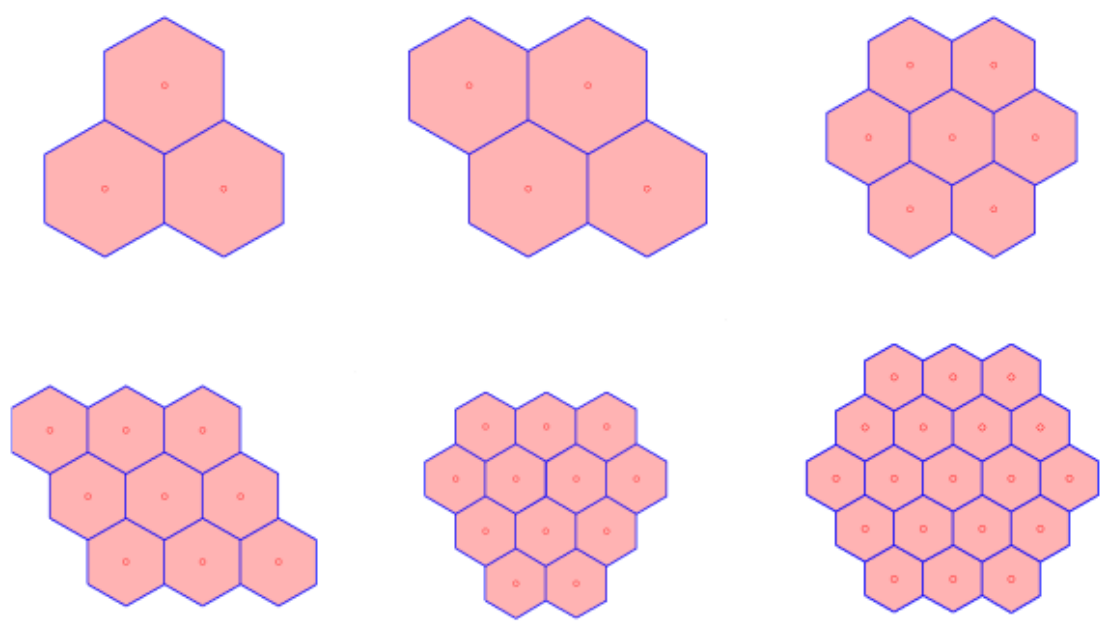

Figure 10: The different SFN sizes (From size of 3 to 19) used in simulation

The received local mean power from each transmitter is calculated based on the ITU_R 1546 propagation model [11]. The path loss within the area of the studied SFN is computed using the $50 \%$ time curve while using the $1 \%$ time curve to estimate the path loss of signals coming from outside the area of the studied SFN.

In the simulation process to get the optimal cell radius, the pixel resolution is a critical parameter and deciding how many pixels should be included in the simulation is a fundamental decision. For one defined radius, the higher the resolution of the 
simulation set, the more pixels will be generated and the better the precision of the results obtained. Here the resolution refers to the area in square meters simulated. However, as the number of pixels increases, the time the simulation takes increases, because of the assumptions made in developing the simulation program and the receiver model, even the best result the simulation tool can provide will differ from the corresponding practical situation. In some cases, small sacrifices in result precision can lead to significant gains in simulation speed. Table 2 lists the different resolutions used and their corresponding total pixel number. The pixel numbers given in Table 2 are taken from simulation results that correspond to the absolute error being below the limit error set at $1 \%$ for the least number of pixels. Here it is assumed that the simulation results obtained using the resolution of $200 \mathrm{~m} * 200 \mathrm{~m}$ are the "true" results and the other simulation results with different resolutions are compared with the "true" value.

Several typical radiuses, $5 \mathrm{~km}, 10 \mathrm{~km}, 20 \mathrm{~km}$ and $40 \mathrm{~km}$, are set in order to find a reasonable resolution for successive intervals of search. Within the intervals marked out by these typical radiuses, a common pixel number can be found for each interval to get a result under the $1 \%$ error limit.

Table 2: The resolution for different cell radius ranges

\begin{tabular}{|l|l|l|l|l|l|}
\hline $\begin{array}{l}\text { Cell radius range } \\
(\mathrm{km})\end{array}$ & $\mathrm{R}=1 \sim 5$ & $\mathrm{R}=5 \sim 10$ & $\mathrm{R}=10 \sim 20$ & $\mathrm{R}=20 \sim 40$ & $\mathrm{R}=40 \sim 80$ \\
\hline Pixels needed & ----- & 667 & 1000 & 1333 & 1333 \\
\hline $\begin{array}{l}\text { Corresponding } \\
\text { Resolution }\left(\mathrm{m}^{2}\right)\end{array}$ & $200 * 200$ & $400 * 400$ & $800 * 800$ & $1200 * 1200$ & $2000 * 2000$ \\
\hline
\end{tabular}

*Pixels needed means to get the absolute error compared to the $200 \mathrm{~m} * 200 \mathrm{~m}$ resolution results below $1 \%$.

\section{Optimal cell radius map:}

The optimal cell radius is a function of the antenna height and transmitting power after the other parameters have been defined. Different combinations of antenna height and transmitter power are simulated to get the corresponding optimal cell radius. Based on the discrete values, the contour line of the radius map is constructed. 10 scenarios listed in Table 3 are simulated to answer the following questions:

1. How do different coverage requirements and C/I ratio thresholds effect the cell dimensioning with and without frequency reuse in different scenarios?

2. How do the SFN size and the guard interval effect the cell dimensioning between the scenarios?

3. How does frequency reuse effect the cell dimensioning? 
Figure 11 and Figure 12 give two examples of the optimal cell radius both for ACG I coverage and SFN size $=7$ but with the guard interval $=1 / 32$, frequency reuse $=1$ and guard interval $=1 / 4$, frequency reuse $=7$, respectively. The other results are not given here for reasons of space but the conclusions based on these simulation result comparisons are given below.

For different coverage requirements for one particular scenario, if the optimal cell radius exits for the parameter set (i.e. transmitter power, antenna height and $\mathrm{C} / \mathrm{I}$ ratio threshold), a bigger cell optimal radius is obtained for ACG III than ACG I and II. In other words, the less covered pixels required in the studied area, the bigger the area the transmitter can cover. The same phenomena can be observed increasing the C/I ratio threshold. The lower the $\mathrm{C} / \mathrm{I}$ ratio threshold required in the planned area, the bigger the cell radius. Table 4 lists the observations made based on the other comparisons between the scenarios.

Table 3: Scenarios simulated in this paper

\begin{tabular}{|l|l|l|l|l|}
\hline $\begin{array}{l}\text { Scenario } \\
\text { No. }\end{array}$ & $\begin{array}{l}\text { SFN } \\
\text { size }\end{array}$ & $\begin{array}{l}\text { Frequency } \\
\text { reuse }\end{array}$ & $\begin{array}{l}\text { Guard } \\
\text { interval }\end{array}$ & $\begin{array}{l}\text { Coverage } \\
\text { requirement }\end{array}$ \\
\hline S1. & 3 & 1 & $1 / 32$ & ACG I, II, III \\
\hline S2. & 7 & 1 & $1 / 32$ & ACG I, II, III \\
\hline S3. & 3 & 1 & $1 / 4$ & ACG I, II, III \\
\hline S4. & 7 & 1 & $1 / 4$ & ACG I, II, III \\
\hline S5. & 3 & 3 & $1 / 4$ & ACG I, II, III \\
\hline S6. & 3 & 7 & $1 / 4$ & ACG I, II, III \\
\hline S7. & 3 & 9 & $1 / 4$ & ACG I, II, III \\
\hline S8. & 7 & 3 & $1 / 4$ & ACG I, II, III \\
\hline S9. & 7 & 7 & $1 / 4$ & ACG I, II, III \\
\hline S10. & 7 & 9 & $1 / 4$ & ACG I, II, III \\
\hline
\end{tabular}


Table 4: The observations made between different scenarios

\begin{tabular}{|c|c|c|}
\hline $\begin{array}{l}\text { Compared } \\
\text { Scenario }\end{array}$ & Comparison content & $\begin{array}{l}\text { The observed conclusion for optimal cell } \\
\text { radius }\end{array}$ \\
\hline $\mathrm{S} 1$ and $\mathrm{S} 2$ & $\begin{array}{l}\text { The effect of self-interference on } \\
\text { the optimal cell radius by increasing } \\
\text { SFN size with guard interval } 1 / 32\end{array}$ & $\begin{array}{l}\text { In the region of low transmit power and low } \\
\text { antenna height }(\mathrm{Pt}<20 \mathrm{~dB} ; \mathrm{Ht}<100 \mathrm{~m}) \text {, } \\
\text { increasing the } \mathrm{SFN} \text { size can increase the } \\
\text { optimal cell radius, but in the high transmit } \\
\text { power and high antenna height region in } \\
\text { Figures } 11 \text { and } 12 \text {, the optimal cell radius } \\
\text { begins to shrink because of the high } \\
\text { self-interference. }\end{array}$ \\
\hline $\mathrm{S} 3$ and S4 & $\begin{array}{l}\text { The effect of self-interference on } \\
\text { the optimal cell radius by increasing } \\
\text { SFN size with guard interval } 1 / 4\end{array}$ & $\begin{array}{l}\text { Increasing the SFN size from } 3 \text { to } 7 \text { can } \\
\text { increase the optimal cell radius in the range } \\
\text { of the transmit power and antenna height for } \\
\text { all } \mathrm{C} / \mathrm{I} \text { ratio thresholds and ACG coverage } \\
\text { requirements. }\end{array}$ \\
\hline $\begin{array}{l}\mathrm{S} 1 \text { and } \mathrm{S} 3 \\
\mathrm{~S} 2 \text { and } \mathrm{S} 4\end{array}$ & $\begin{array}{l}\text { The effect of guard interval on the } \\
\text { optimal cell radius. }\end{array}$ & $\begin{array}{l}\text { The optimal radius for } \mathrm{GI}=1 / 4 \text { is bigger than } \\
\text { that for } \mathrm{GI}=1 / 32 \text { generally. For a } \mathrm{C} / \mathrm{I} \text { ratio } \\
\text { threshold }=5 \mathrm{~dB} \text {, the advantage of a larger } \\
\text { guard interval is not apparent. But for a } \mathrm{C} / \mathrm{I} \\
\text { ratio threshold bigger than } 5 \mathrm{~dB} \text {, the high } \\
\text { power and high antenna height region suffers } \\
\text { from self-interference more than the low } \\
\text { transmit power and low antenna height } \\
\text { region so the radius is much less in } \mathrm{GI}=1 / 32 \\
\text { than in } \mathrm{GI}=1 / 4 \text {. }\end{array}$ \\
\hline $\begin{array}{l}\mathrm{S} 5, \mathrm{~S} 6 \text { and } \mathrm{S} 7 \\
\mathrm{~S} 8, \mathrm{~S} 9 \text { and } \mathrm{S} 10 ;\end{array}$ & $\begin{array}{l}\text { The effect of frequency reuse on the } \\
\text { optimal cell radius. }\end{array}$ & $\begin{array}{l}\text { The bigger the frequency reuse factor, the } \\
\text { bigger the optimal cell radius for one defined } \\
\text { network topology. The simulation also shows } \\
\text { that increasing the SFN size for one } \\
\text { frequency reuse factor can result in a big gain } \\
\text { in the optimal cell radius. }\end{array}$ \\
\hline
\end{tabular}



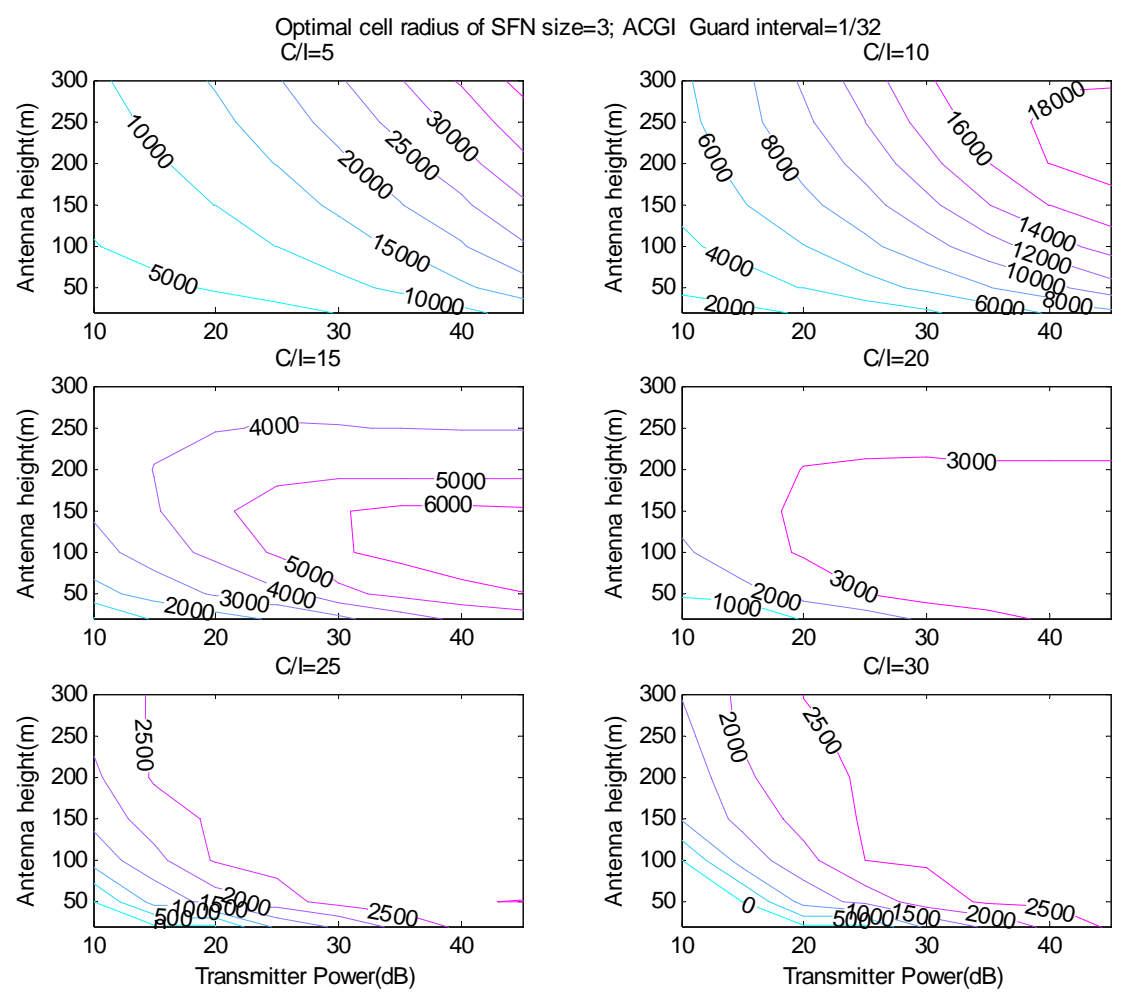

Figure 11: The optimal cell radius with the guard interval $=1 / 32$ of SFN size $=3$; ACG I coverage
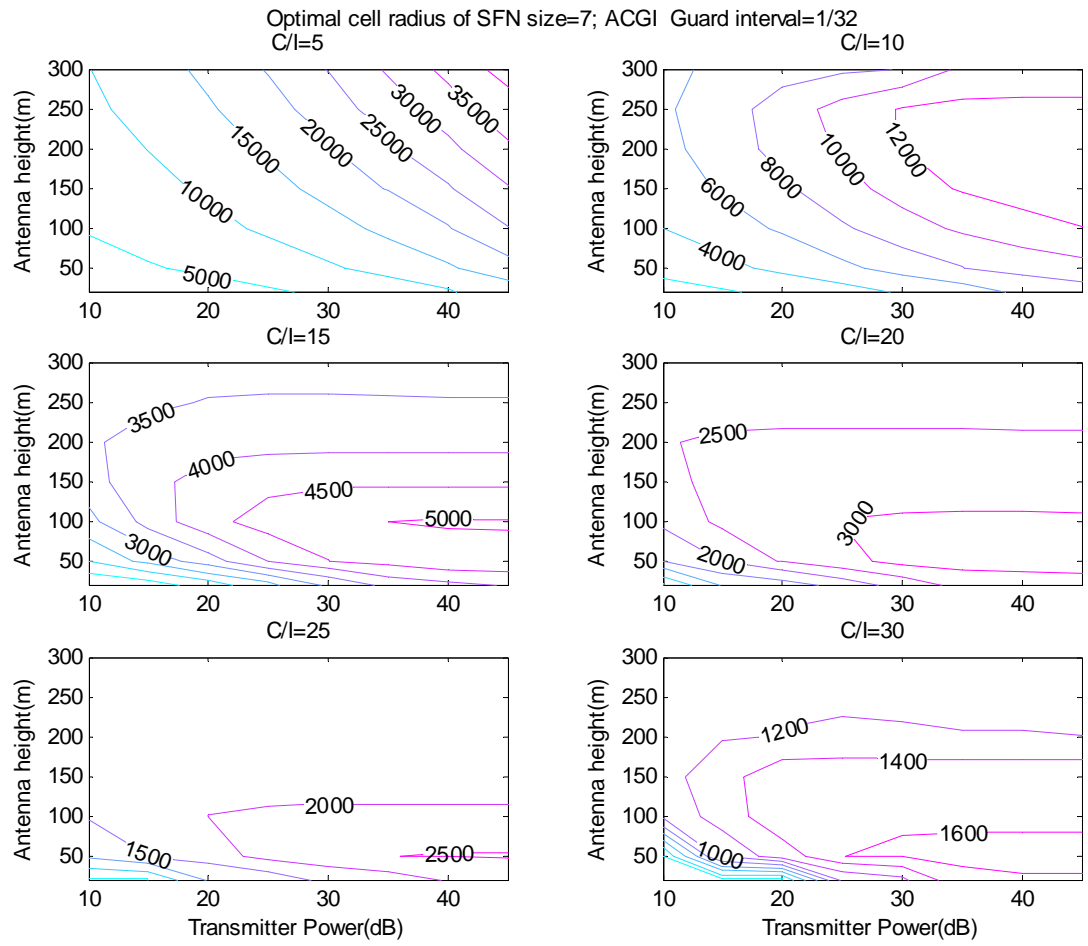

Figure 12: The optimal cell radius with the guard interval $=1 / 32$ of SFN size $=7$; ACG I coverage

\section{SFN gain map:}


After the optimal cell radius is obtained for the defined network topology, the SFN gain can be computed using (9) and (10) and the SFN gain map can be constructed.

Figure 13 gives an example of a SFN gain map with the guard interval $=1 / 32$ of a $\mathrm{SFN}$ size $=3$ for ACG II coverage. Figure 11 shows there are regions with negative gains. A positive SFN Gain under same parameter configuration means that the SFN network is effective for such a configuration; it can cover a bigger area compared with using the single cell transmitter with no frequency reuse and the same number transmitters in a MFN with a frequency reuse. From the cost point of view, it is not recommended to deploy a SFN network for configurations for which the gain is negative. Using the SFN gain map, it can be clearly shown which parameter region can give an effective SFN coverage in the presence of self-interference.
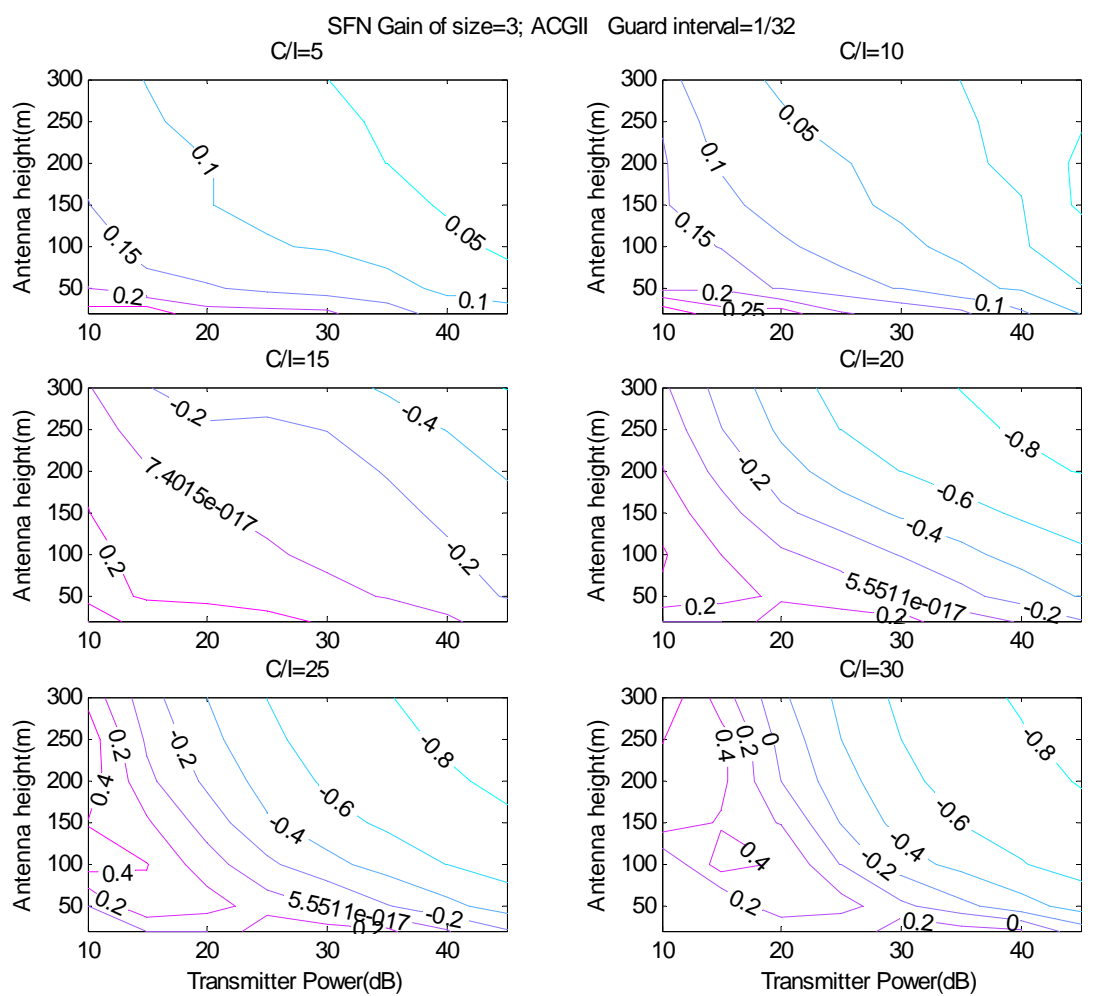

Figure 13: The SFN gain with the guard interval $=1 / 32$ of SFN size $=3$; ACG II coverage

To disclose the SFN effectiveness further for different network topologies, Figure 14 and Figure 15 show the maximum SFN gain for different ACG requirements without frequency reuse. The maximum SFN gain is obtained from the SFN gain map (i.e. Figure 11) for one defined network topology and this gives the value that measures the effectiveness of the SFN for one defined network topology.

For guard interval 1/32, Figure 14 shows that:

- For ACG III coverage the maximum SFN gain increases as the SFN size increases for C/I ratio thresholds 5 to 20 ; For C/I ratio threshold 25 
the gain first increases for size 3 to size 7 then decreases at size 9 , and increases at size 12 and 19 . For a $\mathrm{C} / \mathrm{I}$ ratio threshold of 30 , the maximum gain first increases from size 3 to size 7, then decreases as the SFN increases from size 9 to 19.

- For ACG II coverage, SFN gain increases with increasing SFN size only for C/I ratio threshold 5. For C/I ratio thresholds 10 to 20 the SFN gain first increases at size 7 , then decreases at sizes 9 and 12 and increases at size 19 . For the $\mathrm{C} / \mathrm{I}$ ratio threshold 25 , the $\mathrm{SFN}$ gain increases at size 7 and decreases as the SFN size increases and for $\mathrm{C} / \mathrm{I}$ ratio threshold 30, the SFN gain decreases as the SFN size increases.

- For ACG I coverage, the maximum SFN gain of C/I ratio thresholds 5 and 10 first increases at size 7 and then decreases at size 9 and increases at sizes 12 and 19; The maximum gain for $\mathrm{C} / \mathrm{I}$ ratio thresholds 15 and 20 first increases at size 7 and then decreases as the SFN size increases. The maximum SFN gain of C/I thresholds 25 and 30 always decreases as the SFN size increases.

For guard interval $1 / 4$, Figure 15 shows that:

For ACG III coverage, the maximum SFN gain increases as the SFN size increases. For ACG II and I, the maximum SFN gain exhibits the trend of firstly increasing, then decreasing and finally increasing with SFN network size for all $\mathrm{C} / \mathrm{I}$ ratio thresholds

Figure 14 and Figure 15 show that symmetrical network topologies can provide a larger SFN gain than asymmetrical topologies. 

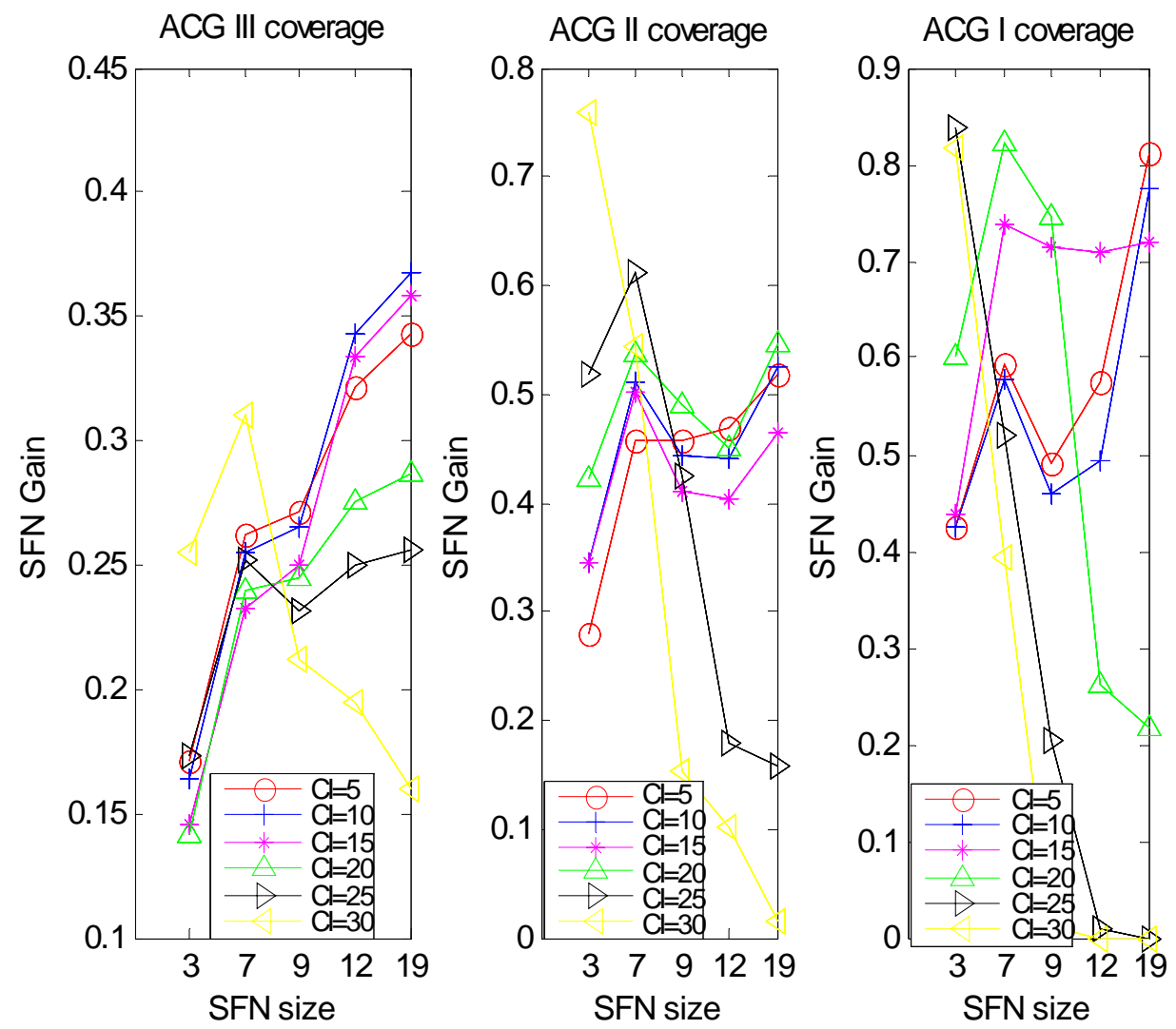

Figure 14: The maximum SFN gain for ACG coverage without frequency reuse and GI = 1/32 (Antenna height range $20 \mathrm{~m} \sim 300 \mathrm{~m}$, transmitter power range $10 \mathrm{~dB} \sim 45 \mathrm{~dB}$ )
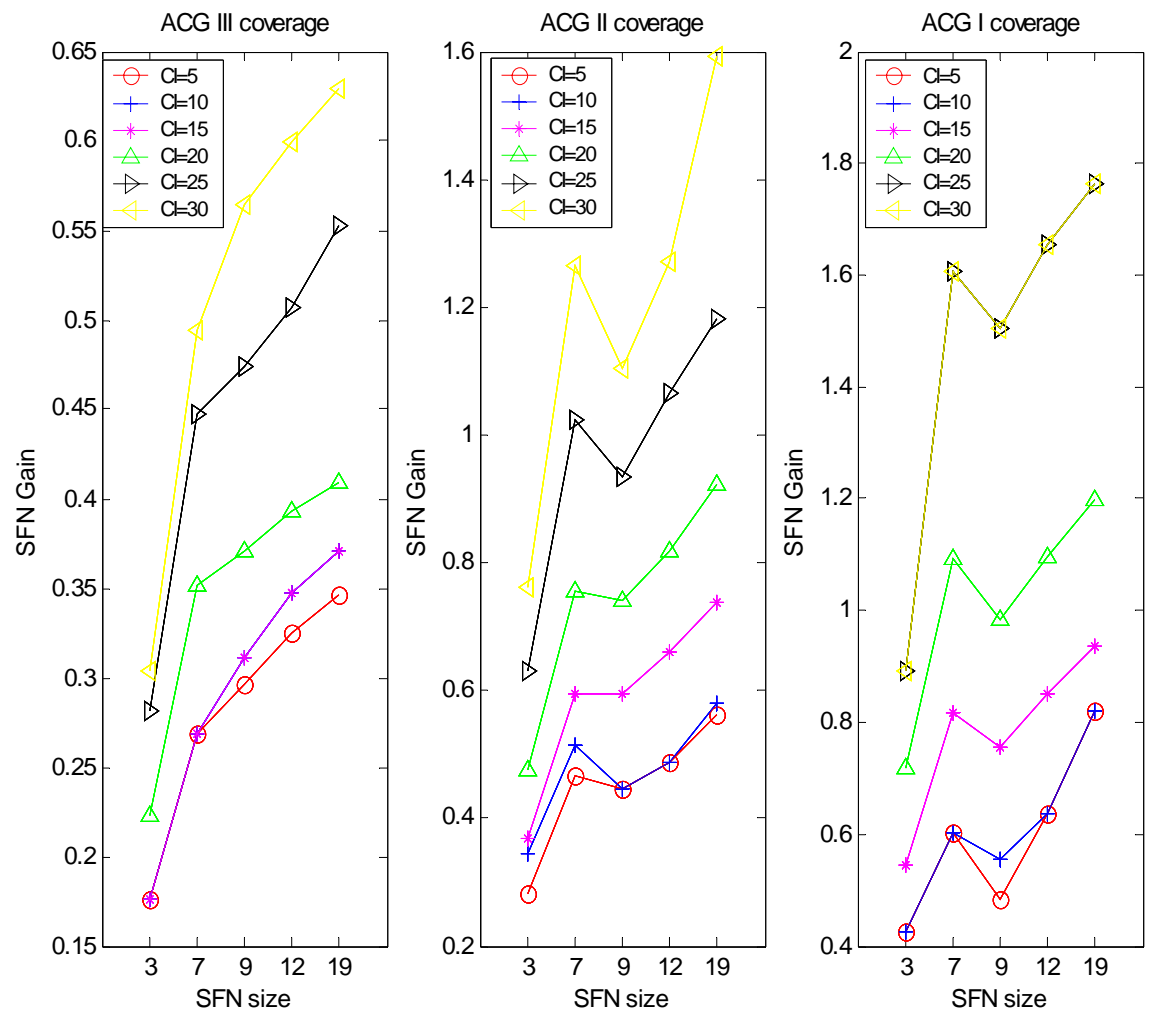
Figure 15: The maximum SFN gain for ACG coverage without frequency reuse and GI = 1/4

(Antenna height range $20 \mathrm{~m} \sim 300 \mathrm{~m}$, transmitter power range $10 \mathrm{~dB} \sim 45 \mathrm{~dB}$ )

\section{Optimisation of the network parameters:}

A large SFN gain means that using the same transmitter power and antenna height, one transmitter in the SFN can cover a much larger area than a MFN network with the same reuse factor and the whole network can benefit from the deployment of a single frequency network.

Though there is a range of antenna height and transmitter power combinations that give a predefined cell radius, the best choice is the combination that gives the largest SFN gain at the same time. For example, Figure 16 shows the optimal point for the $8 \mathrm{~km}$ radius at the SFN gain $=0.7$. The optimal point means that the SFN can get the maximum coverage gain compared with the MFN with the same antenna height and transmit power. In other words, if the MFN is deployed instead of the SFN using the same antenna height and transmitter power and the other network parameters are kept the same, the MFN cell radius will shrink to $\mathrm{R}_{\mathrm{SFN}} /(1+\mathrm{G})$, here $\mathrm{R}_{\mathrm{SFN}}$ is the $\mathrm{SFN}$ cell radius, and $\mathrm{G}$ means the SFN gain. That also means optimisation of these network parameters using this method can minimise the network cost.

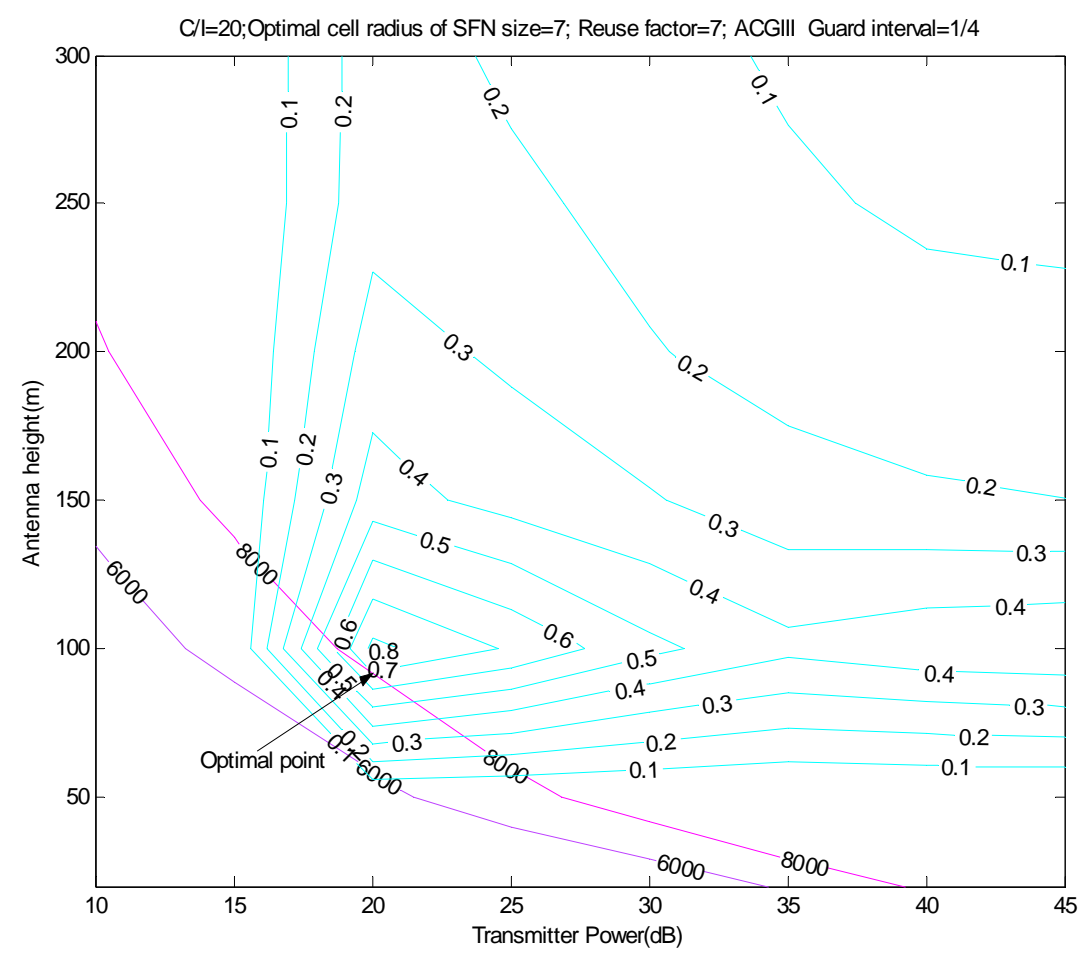

Figure 16: A combination graph of SFN gain and SFN optimal cell radius for ACG III coverage (the red and purple line represents the contour of the optimal cell radius, the light blue line represents the contour of the SFN gain) 


\section{CONCLUSIONS}

In this paper, a coverage planning process for DVB-H SFNs has been presented. Based on simulation results the network performance for different cell sizes and frequency reuse factors was investigated for one DVB-H transmitter configuration leading to the following conclusions:

External and internal interference play an important role in the coverage planning and dimensioning of DVB-T/H networks.

DVB-H network planning has an additional burst duration parameter to consider compared with DVB-T network coverage planning.

For one cell radius, there is a range of transmitter power and antenna height that can achieve the predefined coverage requirement; the optimal choice of the transmitter power and antenna height is that which gives the maximum SFN gain.

Increasing the number of the transmitters in a SFN can raise the C/I ratio threshold coverage in the case of frequency reuse and $1 / 4$ guard interval.

In the small guard interval and no frequency reuse case, for a high $\mathrm{C} / \mathrm{I}$ ratio threshold like 25 or 30 and a high coverage requirement (ACG I or II), increasing the number of the SFN transmitters will decrease the maximum SFN gain for the reason of increasing self-interference. In other words, the SFN network cannot provide better network performance than a single cell for some transmitter power and antenna height combinations. The network parameters need to be carefully selected based on simulation results and field trials.

For the no frequency reuse case, a symmetrical topology will give better coverage for the reason of less self-interference incurred than an asymmetric topology.

\section{References:}

[1] Digital video broadcasting: DVB-H implementation guide; ETSI TR 102 377; v1.1.1; 02, 2005 ;

[2] http://www.ist-instinct.org/; 17-11-05;

[3] Ligeti, A., and Zander, J.; Minimal cost coverage planning for single frequency networks; Broadcasting, IEEE Transactions on, Volume: 45, Issue: 1, March 1999; Pages:78 - 87

[4] Ligeti, A; Coverage probability estimation in single frequency networks in presence of correlated useful and interfering components; Vehicular Technology Conference, 1999. VTC 1999 - Fall. IEEE VTS 50th, Volume 4, 19-22 Sept. 1999; Pages: 2408 - 2412 vol.4

[5] Speth, M.; Fechtel, S.A.; Fock, G.; Meyr, H.; "Optimum receiver design for wireless 
broad-band systems using OFDM. I"; IEEE Transactions on Communications; Volume 47, Issue 11, Nov. 1999 Page(s):1668 - 1677.

[6] ECC REP004 Annex-Criteria for planning DVB-T

[7] Terrestrial digital television planning and implementation considerations, BNP005, third issue, summer 2001

[8 ] S.C. Schwartz and Y.S. Yeh, "On the distribution function and moments of power sums with log-normal components”, Bell Syst. Tech. J., vol. 61, no. 7, pp. 1441-1462, Sept. 1982

[9 ] Chia-Lu Ho; "Calculating the mean and variance of power sums with two log-normal components; Vehicular Technology, IEEE Transactions on; Volume 44, Issue 4, Nov. 1995 Page(s): $756-762$

[ 10 ] Gordon L. Stuber; Principles of Mobile Communication; second edition ISBN 7-5053-9698-6;

[11] C Zhang, T.Owens and YH.Song; "A simplified algorithm for the implementation of the Schwartz and Yeh method for the sum of lognormal distributed variables", submitted to IEEE Transactions on Vehicular Technology;

[12] Roland Brugger and David Hemingway; "OFDM receivers -impact on coverage of inter-symbol interference and FFT window positioning”; EBU technical review; July 2003. 